\title{
Derin Çekme İşlemi Sonrası Malzemede Oluşan Sertlik Dağılımı Üzerine Kalıp Yüzey Açısı, Sıcaklık Ve Baskı Plakası Kuvveti Etkilerinin İncelenmesi
}

\author{
${ }^{1}$ Cebeli Özek, ${ }^{* 2}$ Vedat Taşdemir \\ ${ }^{1}$ Frrat Üniversitesi,Teknoloji Fakültesi, Makine Mühendisliği Bölümü, Türkiye, cozek@ firat.edu.tr, \\ ${ }^{*}$ Kahramanmaraş Sütçü İmam Üniversitesi, Elbistan Meslek Yüksekokulu, Makine Programı, Türkiye, vtasdemir@ksu.edu.tr,
}

Bu çalışmada, derin çekme yöntemi ile elde edilen kapların sertliğine kalıp yüzey açısı, sıcaklık ve baskı plakası kuvvetinin etkilerinin belirlenmesi amaçlanmıştır. Çalışmada, 4 farklı kalıp yüzey açısı $\left(0^{\circ}, 5^{\circ}, 10^{\circ}, 15^{\circ}\right), 4$ farklı $\operatorname{sicaklık}\left(25^{\circ} \mathrm{C}, 100^{\circ} \mathrm{C}\right.$, $\left.175^{\circ} \mathrm{C}, 250^{\circ} \mathrm{C}\right)$ ve 3 farklı baskı plakası kuvveti $(1200 \mathrm{~N}, 2400 \mathrm{~N}, 3600 \mathrm{~N})$ kullanılmıştır. Yapılan deneyler sonucunda sıcaklığın artmasıyla kapların sertliğinin düştüğü, baskı plakası kuvvetinin artması ile kapların sertliğinin çok az arttığı ve hem sertlik hem de şekillendirme açısından en ideal kalıp açısının 5-10 olduğu belirlenmiştir. Ayrıca elde edilen kaplardaki en düşük sertliğin kap tabanında olduğu, kap ağzına doğru çıkıldıkça sertliğin arttığı görülmüştür. Limit çekme oranı 2,14'den 2,75'e çıktığında sıcaklığın etkisi ile sertlikte artış olmamıştır. Sonuç olarak, belirlenen parametrelerin deformasyon sırasında oluşan sertliğin kontrolünde önemli rol oynadığı net bir şekilde görülmüştür.

Anahtar kelimeler: Derin çekme, sertlik dağılımı, kalıp yüzey açısı, limit çekme oranı

\section{Investigation Of Effects Of Die Surface Angle, Temperature And Blank Holder Force On The Hardness Distribution Forming İn Material After Deep Drawing Process}

\author{
${ }^{1}$ Cebeli Özek, ${ }^{2}$ Vedat Taşdemir \\ ${ }^{1}$ Fırat University, TechnologyFaculty, MechanicalEngineering, Elazı̆g/Turkey, cozek@firat.edu.tr \\ ${ }^{*}$ Kahramanmaraş Sütçü İmam University, Elbistan Vocational School, Machine Program, Kahramanmaraş/Turkey, \\ vtasdemir@ksu.edu.tr
}

\begin{abstract}
In this study, it is aimed to determine the effects of die surface angle, temperature and blank holder force on the hardness of the obtained cups by deep drawing method. In the study, 4 different die surface angles $\left(0^{\circ}, 5^{\circ}, 10^{\circ}, 15^{\circ}\right)$, four different temperatures $\left(25^{\circ} \mathrm{C}, 100^{\circ} \mathrm{C}, 175^{\circ} \mathrm{C}, 250^{\circ} \mathrm{C}\right)$ and three different blank holder force $(1200 \mathrm{~N}, 2400 \mathrm{~N}, 3600 \mathrm{~N})$ were used. As a result of the studies, it was determined that the hardness of the cups decreased with the increase of the temperature, the hardness of the cups increased with the increase of the blank holder force and the most ideal die surface angle is 5-10 in terms of both hardness and forming. Moreover, it has been observed that the lowest hardness in the obtained cups is at the bottom of the cup and the hardness increases as moved towards the mouth of the cup. When the limit drawing ratio increased from 2.14 to 2.75 , there was no increase in hardness due to the effect of temperature. As a result, it is clearly seen that the determined parameters play an important role in controlling the hardness during deformation.
\end{abstract}

Keywords: Deep drawing, hardness distribution, die surface angle, limit drawing ration

\section{GİRIŞ}

Sac metal şekillendirme, malzemelerin incelme(boyun verme) ve çatlama olmadan plastik olarak deformasyona uğrama kabiliyetini gösterir[1]. Derin çekme, sacların şekillendirilmesinde yaygın olarak kullanılan sac metal şekillendirme yöntemlerden biridir[2]. Bu yöntemle, iki boyutlu, düzlemsel geometriye sahip iş parçalarından belirli derinlik ve profillere sahip üç boyutlu ürünler elde edilir[3]. Basit ve karmaşık şekilli birçok parça kolaylıkla bu

*Sorumlu Yazar: Kahramanmaraş Sütçü İmam Üniversitesi, Elbistan Meslek Yüksekokulu, Makine Programı, vtasdemir@ksu.edu.tr, (+90)344 3004085 
yöntemle imal edilebildiğinden yiyecek ve içecek sanayinde, otomotiv, denizcilik, hava, savunma ve diğer birçok alanda bu yöntem oldukça önemli bir yere sahiptir. İşlemin başarılı olmasında, seçilen malzeme özellikleri ve işlem parametreleri önemli rol oynar. Şekillendirmeyi etkileyen en önemli parametrelerden bazılarını; işleme sertleşmesi, deformasyon hızı hassasiyeti, anizotropi, deney parametreleri, kalıp geometrisi, şekillendirme sıcaklığ şeklinde sıralayabiliriz[4-7]. Tsuchida ve arkadaşları, 3004H19 alüminyum alaşımının incelterek çekme işleminin hadde doğrultusuna bağlı olarak kap duvarlarındaki sertlik ve uzamaya olan etkilerini incelemişlerdir. En düşük sertliğin enine doğrultuda ve incelme değerinin en fazla olduğu kalıplarda elde edildiğini belirtmişlerdir[8].

Lela ve arkadaşları, AA8011A alüminyum sac kullanarak derin çekilmiş kapların sertlik ve kulaklanma oluşumuna baskı plakası kuvveti, tavlama sıcaklığı ve tavlama süresinin etkilerini parametrik ve parametrik olmayan iki farklı yaklaşım kullanarak modellemişlerdir[9]. Emmens ise derin çekme ve kademeli çekme yöntemi ile elde edilen numunelerdeki sertlik üzerine bir çalışma yapmıştır. İki yöntem sonucunda aynı sertliğin elde edildiğini, mekanik özelliklerin sac kalınlığına göre değişiklik gösterdiğini ve sertlik ölçümünün tek başına yanıltıcı olabileceğini belirtmiştir[10].

Şekillendirmeyi etkileyen deformasyona bağlı parametrelerden biri olan sertlik; uzama, tanelerin deformasyonu[10], malzemenin kalıp boşluğuna akışı, zımba kuvveti, kaptaki kalınlık değişimleri ve kaptaki gerilmeler ile yakından ilişkilidir. Bundan dolayı bu çalışma, belirlenen sıcaklıklar, baskı plakası kuvvetleri ve kalıp yüzey açılarının derin çekme ile elde edilen kapların deformasyon sertliğine etkisinin belirlenmesi amacı ile yapılmıştır. Derin çekme üzerine yapılan çalışmalar incelendiğinde kullanılan parametrelerin elde edilen kapların sertliğinin belirlenmesi üzerine çok az sayıda çalışmanın olduğu görülmüştür. Özellikle kalıp yüzey açısının yanısıra limit çekme oranı sonucu elde edilen kapların sertliği üzerine yapılmış hiçbir çalışmanın olmadığı belirlenmiştir. Bundan dolayı yapılan bu çalışma diğer çalışmalardan oldukça farklı ve özgün bir niteliğe sahiptir.

\section{MALZEME VE YÖNTEM}

Deneylerde, $1 \mathrm{~mm}$ kalınlığında ticari olarak temin edilmiş EN AW-5754 (AlMg3) sac malzeme kullanılmıştır. Malzeme, "H111" formunda temin edilmiş olup, çekme deneylerinden önce malzeme $380^{\circ} \mathrm{C}$ sicaklıkta 4 saat tavlamaya tabi tutularak "O" formuna getirilmiştir. Kullanılan malzemenin kimyasal bileşimi Tablo 1'de verilmiştir.

Sac malzemenin mekanik özelliklerini belirlemek amacıyla $5000 \mathrm{kN}$ kapasiteli SHIMATZU marka çekme test cihazında $5 \mathrm{~mm} /$ dak çekme hızında $0^{\circ}, 45^{\circ}$ ve $90^{\circ}$ olmak üzere üç farklı haddeleme yönünde toplam 9 adet numune çekme testine tabi tutulmuş ve ortalaması alınmıştır. Malzemenin mekanik özellikleri Tablo 2'de verilmiştir.

Tablo 1. EN AW-5754 (AlMg3) sacının kimyasal analizi, \%

\begin{tabular}{|l|l|l|l|l|l|l|l|l|l|l|l|}
\hline \multicolumn{1}{|l|}{ Kimyasal Bileşim, \% } \\
\hline $\mathrm{Si}$ & $\mathrm{Fe}$ & $\mathrm{Cu}$ & $\mathrm{Mn}$ & $\mathrm{Mg}$ & $\mathrm{Cr}$ & $\mathrm{Ni}$ & $\mathrm{Zn}$ & $\mathrm{Ti}$ & $\mathrm{Ga}$ & $\mathrm{V}$ & Al \\
\hline 0,13 & 0,3 & 0,019 & 0,14 & 2,72 & 0,005 & 0,005 & 0,022 & 0,018 & 0,01 & 0,013 & $\begin{array}{l}\text { Geriye } \\
\text { kalan }\end{array}$ \\
\hline
\end{tabular}

Tablo 2. Deney numunesinin oda sıcaklığındaki mekanik özellikleri

\begin{tabular}{|c|c|c|c|c|c|c|}
\hline \multirow{2}{*}{$\begin{array}{l}\text { Hadde } \\
\text { yönü } \\
\left({ }^{\circ}\right)\end{array}$} & \multirow{2}{*}{$\begin{array}{l}\text { Akma } \\
\text { dayanımı } \\
\left(\mathrm{N} / \mathrm{mm}^{2}\right)\end{array}$} & \multirow{2}{*}{$\begin{array}{l}\text { Çekme } \\
\text { dayanımı } \\
\left(\mathrm{N} / \mathrm{mm}^{2}\right)\end{array}$} & \multirow{2}{*}{$\begin{array}{l}\text { Uzama } \\
(\%)\end{array}$} & \multirow{2}{*}{$\begin{array}{l}\text { Elastikiyet } \\
\text { modülü } \\
(\mathrm{GPa})\end{array}$} & \multicolumn{2}{|c|}{ Sertlik, HV0.2 } \\
\hline & & & & & $\begin{array}{l}\text { Is1l işlem } \\
\text { öncesi, "H111" }\end{array}$ & $\begin{array}{ll}\text { Is1l işlem } \\
\text { sonrası, "O" }\end{array}$ \\
\hline 0 & 167,74 & 248,54 & 10,32 & \multirow{3}{*}{66} & \multirow{3}{*}{82,6} & \multirow{3}{*}{61,7} \\
\hline 45 & 163,25 & 235,16 & 12,82 & & & \\
\hline 90 & 165,64 & 240,11 & 11,68 & & & \\
\hline
\end{tabular}

$\mathrm{Bu}$ çalışma ile, kalıp yüzey açısı, sıcaklık ve baskı plakası kuvvetinin derin çekme işlemi sonucunda elde edilen kapların sertliğine olan etkilerinin incelenmesi amaçlanmaktadır. Deneyler, kalıp ve baskı plakası yüzeylerine $0^{\circ}, 5^{\circ}, 10^{\circ}$ ve $15^{\circ}$ açılar verilerek $25^{\circ} \mathrm{C}, 100^{\circ} \mathrm{C}$, $175^{\circ} \mathrm{C}$ ve $250^{\circ} \mathrm{C}$ sicakliklarda ve $1200 \mathrm{~N}, 2400 \mathrm{~N}$ ve $3600 \mathrm{~N}$ baskı plakası kuvvetlerinde yapılmıştır.

Belirlenen sıcaklıklar ve baskı plakası kuvvetleri Al-Mg alaşımı üzerine yapılan birçok çalışma referans alınarak belirlenmiştir. Zımba ve kalıp köşe yarıçapları $8 \mathrm{~mm}$ sabit tutulmuştur. Deneylerde, yüzeyler arasındaki sürtünmeleri azaltmak amacıyla MoS2 (3-4 $\mu \mathrm{m})$ yağlayıcı kullanılmıştır. Şekil 1'de deney düzeneğinin şematik görüntüsü verilmiştir. Tablo 3 'te ise deneylerde kullanılan işlem parametreleri verilmiştir.

Çekilen kaplarında deformasyon sonrası oluşan sertlik ölçümü, EmcotestDuraScan mikrosertlik cihazı ile Şekil 3'de görüldüğü gibi hadde doğrultusu boyunca hassas bir şekilde kesilen ve bakalit içerisine alınan numune üzerinden $5 \mathrm{~mm}$ aralıklarla 200 gr yük uygulanarak(HV0.2) yapılmıştır. Derin çekme işlemi uygulanmadan 1 sıl işlem görmüş sacın ortalama sertliği 61,7 HV olarak ölçülmüştür. 


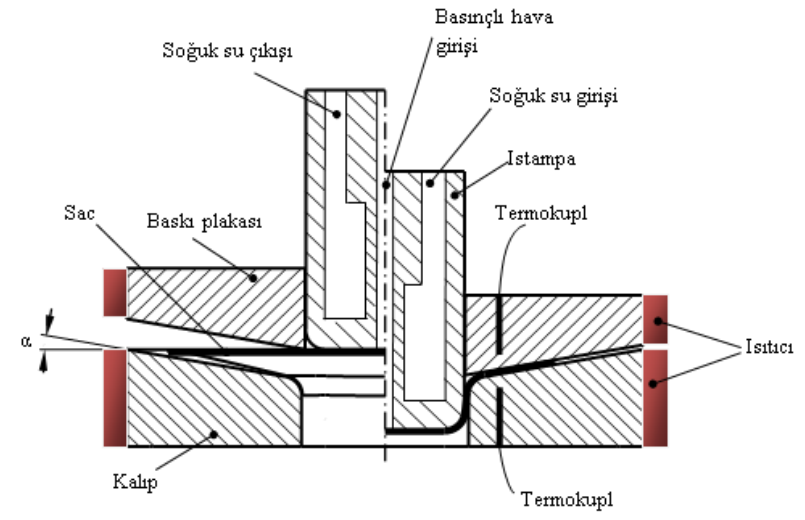

Şekil 1. Deney düzeneği şeması

Tablo 3. Deneylerde kullanılan işlem parametreleri

\begin{tabular}{lll}
\hline Parametre & Ölçü & Birim \\
\hline Kalıp kenar radyüsü, R & 8 & $\mathrm{~mm}$ \\
Istampa köşe radyüsü, r & 8 & $\mathrm{~mm}$ \\
Baskı plakası kuvveti, BPK & $1200,2400,3600$ & $\mathrm{~N}$ \\
İlkel parça çapı, D & 85 & $\mathrm{~mm}$ \\
Istampa hızı, V & 4 & $\mathrm{~mm} / \mathrm{s}$ \\
Zımba çapı, d & $\mathrm{m}$ & $\mathrm{mm}$ \\
Kalıp çapı, d, & 39,60 & $\mathrm{~mm}$ \\
Sac kalınlığ1, t & 42,30 & $\mathrm{~mm}$ \\
Tek taraflı kalıp boşluğu, c & 1,35 & $\mathrm{~mm}$ \\
Kalıp yüzey açısı, $\alpha$ & $0,5,10,15$ & ${ }^{\circ}$ \\
Deney sıcaklı̆̆ $1, \mathrm{~T}$ & $25,100,175,250$ & ${ }^{\circ} \mathrm{C}$ \\
\hline
\end{tabular}

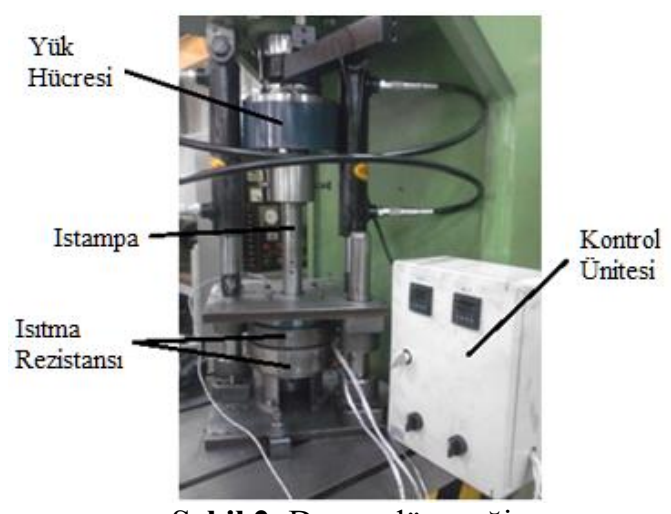

Şekil 2. Deney düzeneği

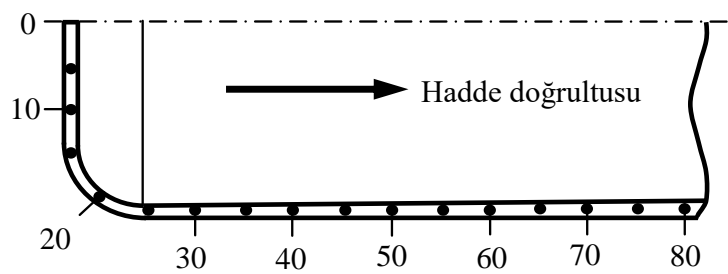

Şekil 3. Ekilen kapların mikrosertlik ölçüm şeması

\section{BULGULAR}

Yapılan derin çekme deneyleri sonucu oda sicaklığında $\left(25^{\circ} \mathrm{C}\right) 2,14$ olan limit çekme oranı $(\mathrm{LCCO}=\beta)$ sirasi ile $100^{\circ} \mathrm{C}^{\prime}$ de $2,17,175^{\circ} \mathrm{C}^{\prime}$ de 2,35 ve $250^{\circ} \mathrm{C}^{\prime}$ de 2,80 oranına çıkmıştır. Çalışmada tüm sıcaklık, baskı plakası ve kalıp açılarında elde edilen kapların sertlikleri tüm LÇO'lar için ölçülmüş̧ür.

Şekil 4'de sıcaklığın kap duvarlarındaki sertlik dağı̆lımı üzerindeki etkisi tüm baskı plakası kuvvetleri için verilmiştir. Şekillerden tüm baskı plakası kuvvetleri için en düşük sertlik değerinin kap tabanında olduğu, kap ağzına doğru çıkıldıkça sertlik değerinin arttığı görülmektedir.

Şekillendirme esnasında en fazla plastik deformasyona uğrayan bölge kap ağız bölgesi olduğu için en büyük gerilme değeri ve sertlik de burada oluşmaktadır[7, 10].

Burada sonuçların yapılan çalışmalarla uyum içinde olduğu görülmektedir. Ayrıca şekillerden, sıcaklık arttıkça sertlik değerinin de düştüğü açık bir şekilde görülmektedir. $\mathrm{Bu}$ durumun sıcaklığın, dinamik deformasyon sertleşmesi olarak bilinen Portevin-Le Chatelier (PLC) etkisini ortadan kaldırması sonucu şekillendirmeyi kolaylaştırmasından kaynaklandığg söylenebilir[11, 12].

Yine şekillerden baskı plakası kuvvetinin sertliğe olan etkisi de görülmektedir. Seçilen baskı plakası kuvveti değerleri göz önüne alındığında çok bariz bir etkinin olmadığı görülecektir. 

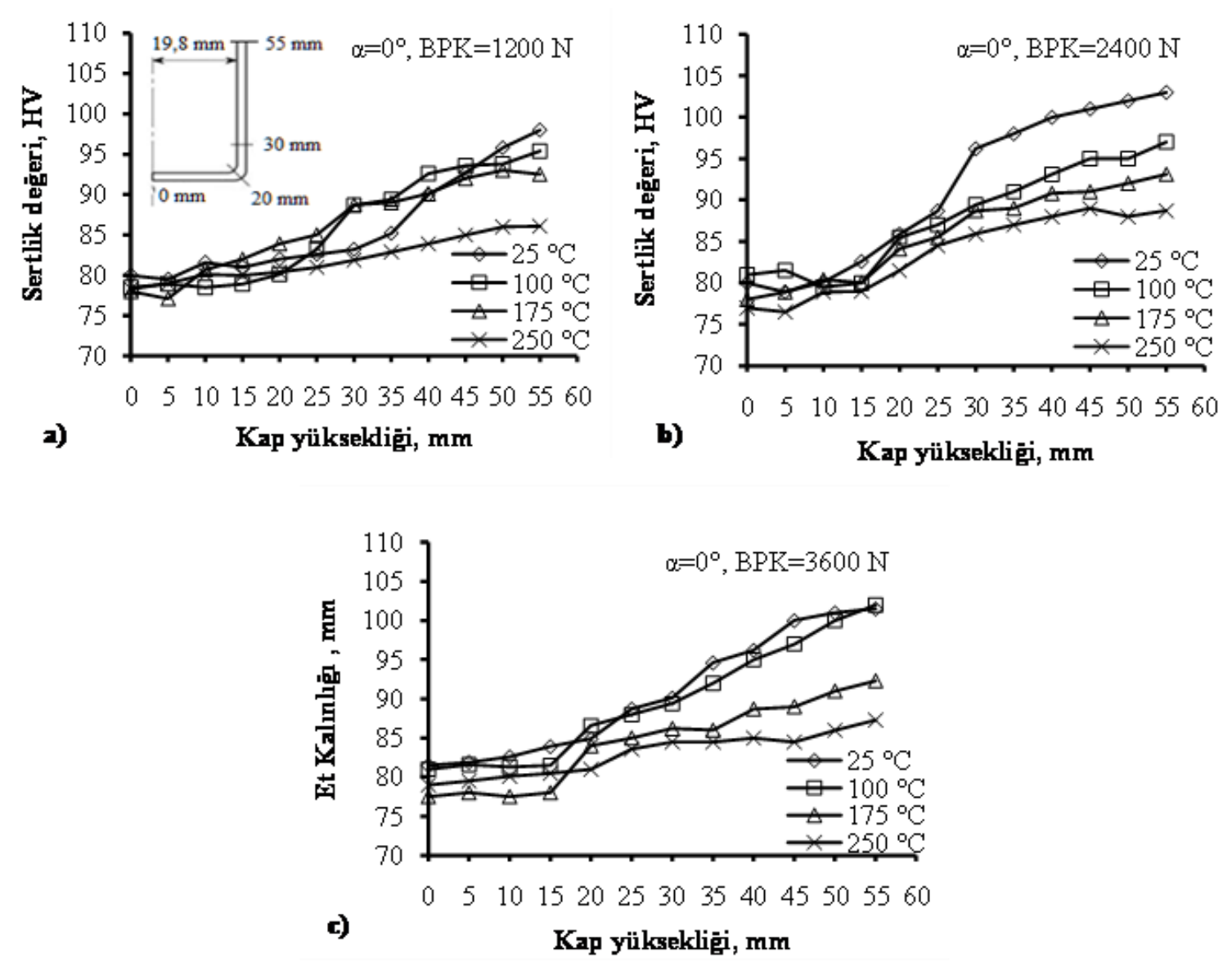

Şekil 4. $\beta=2,14$ için açısız kalıplarla elde edilen numunelerde sıcaklığının sertlik dağılımı üzerindeki etkisi a) $1200 \mathrm{~N}$, b) 2400 $\mathrm{N}$ [7], c) $3600 \mathrm{~N}$

Şekil 5'de farklı çekme oranları sonucu $25^{\circ} \mathrm{C}^{\prime} \mathrm{de} \beta=2,14$, $100^{\circ} \mathrm{C}^{\prime}$ de $\beta=2,17,175^{\circ} \mathrm{C}^{\prime} \mathrm{de} \beta=2,35$ ve $250^{\circ} \mathrm{C}^{\prime}$ de $\beta=2,75$ olarak elde edilen kaplardaki sertlik dağılımı değerleri verilmiştir. En yüksek sertlik değerleri $25^{\circ} \mathrm{C}$ 'de $98 \mathrm{HV}$, $100^{\circ} \mathrm{C}$ 'de $95,4 \mathrm{HV}, 175^{\circ} \mathrm{C}$ 'de $96,2 \mathrm{HV}$ ve $250^{\circ} \mathrm{C}$ 'de $95 \mathrm{HV}$ olarak elde edilmiștir. Şekilden görüldüğü gibi LÇO $\beta=2,14$ 'den $\beta=2,75$ 'e çıkmasına rağmen sertlik değeri sıcaklığın etkisi ile değişmemiş kısmen de olsa azalmıştır. $\mathrm{Bu}$ da sicaklığın şekillendirmede ne derece etkin bir parametre olduğunu açıkça göstermektedir.

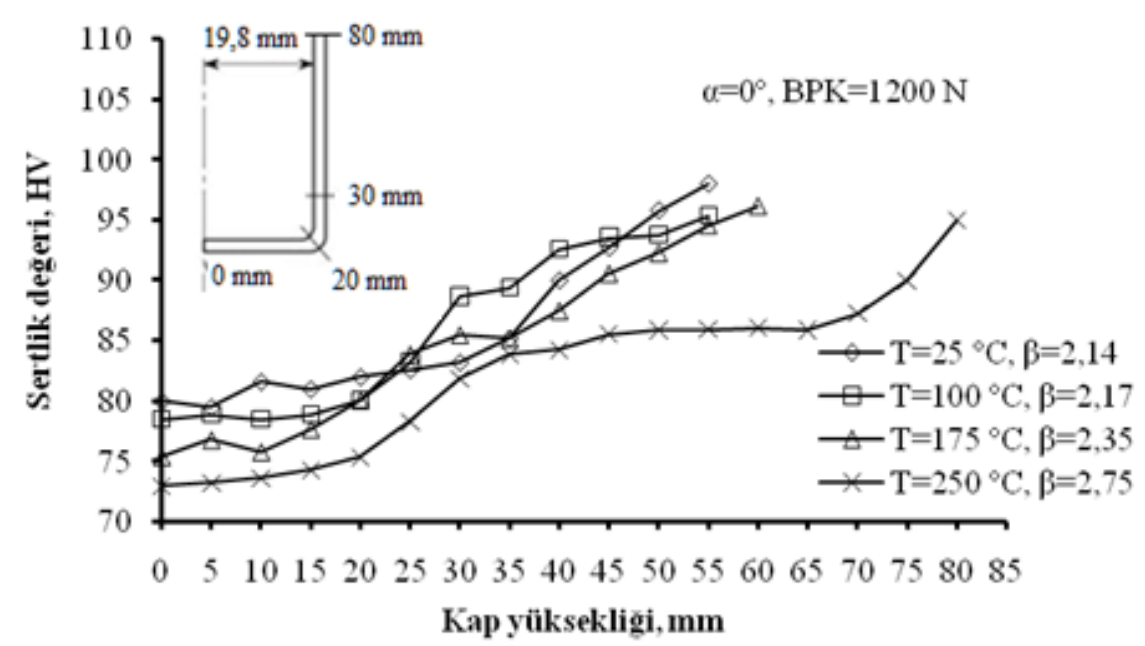

Şekil 5. Farklı LÇO ve sıcaklık değerleri sonucu elde edilen kaplardaki sertlik dağılımı 
Şekil 6 ve Şekil $7^{\prime}$ de sırası ile $25^{\circ} \mathrm{C}$ ve $250^{\circ} \mathrm{C}$ 'de kalıp açısının sertlik dağılımı üzerindeki etkisi verilmiştir. Şekiller birlikte değerlendirildiğinde kap tabanından kap ağzına doğru çıkıldıkça sertlik değerlerinin arttığı, Şekil $6^{\prime}$ da en düşük sertlik değerinin $\alpha=5^{\circ}$ kalıpta, en yüksek sertlik değerinin ise $\alpha=0^{\circ}$ kalıpta elde edildiği tespit edilmiştir. Şekil $7^{\prime}$ 'de ise sıcaklık $250^{\circ} C^{\prime}$ ye çıktığında tüm kalıp açıları için değişim aralığının birbirine yaklaştığı, farkın azaldığ 1 görülmektedir. $250^{\circ} \mathrm{C}$ 'de en yüksek sertlik değerinin $\operatorname{açısız}\left(\alpha=0^{\circ}\right)$ kalıplarda ölçüldüğü belirlenmiştir. Buradan kabın sertlik dağılımına kalıp açısının olumlu etkisinin olduğu söylenebilir. Bu durum, kalıp açısının malzeme akışını kolaylaştırması sonucunda deformasyon sertleşmesinin azalması ile açıklanabilir.

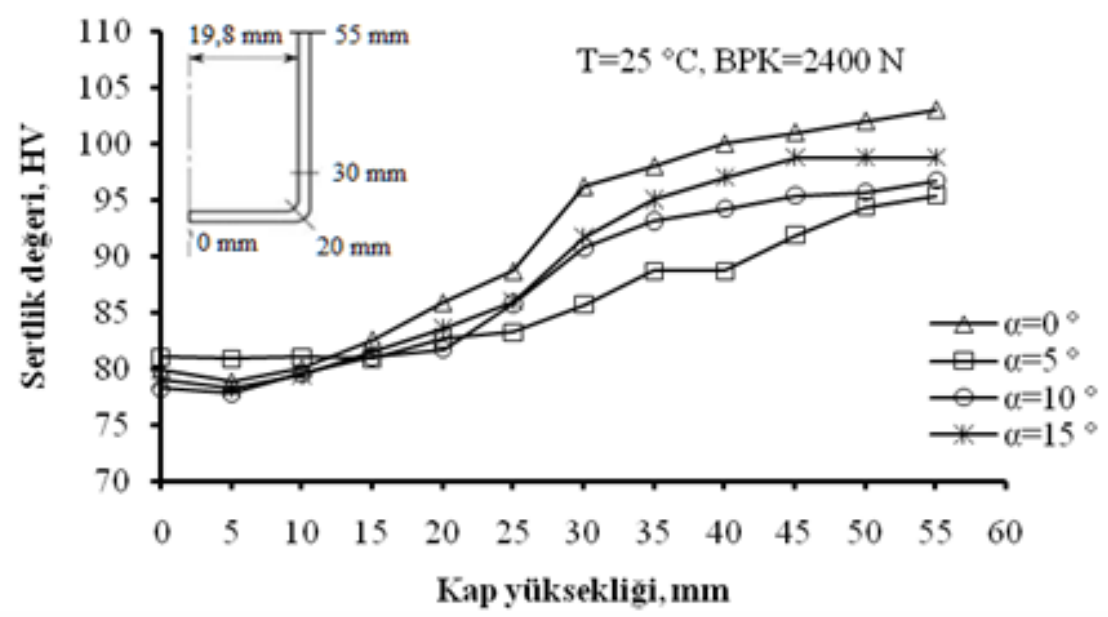

Şekil 6. $\beta=2,14$ için kalıp açısının( $\alpha$ ) oda sıcaklığında sertlik dağılımı üzerindeki etkisi

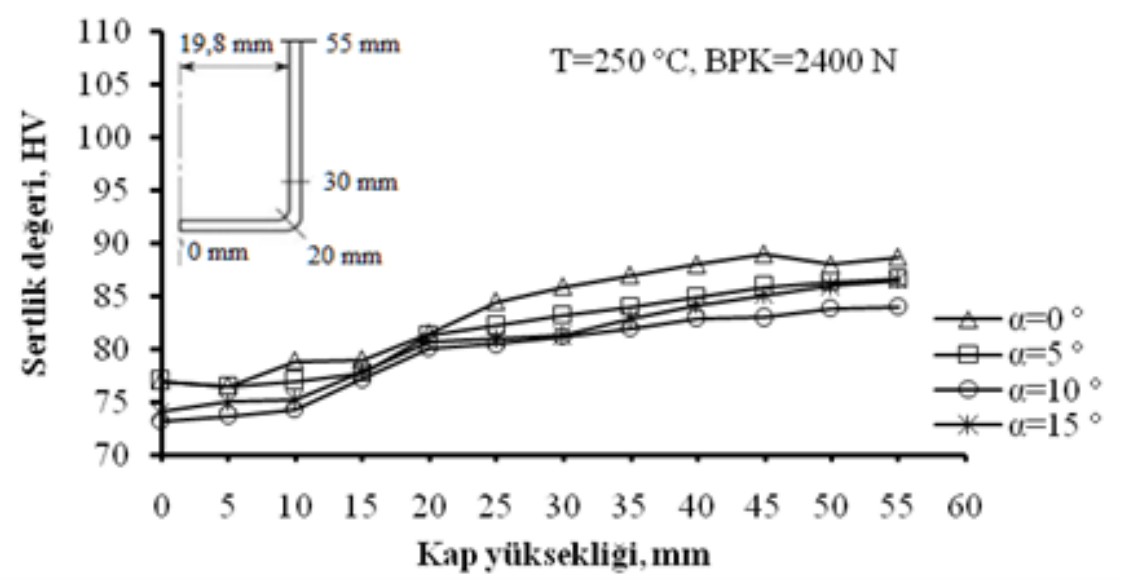

Şekil 7. $\beta=2,14$ LÇO için kalıp açısının $(\alpha) 250^{\circ} C^{\prime}$ de sertlik dağılımı üzerindeki etkisi

Şekil $8^{\prime}$ de $250^{\circ} C^{\prime}$ de $\beta=2,75$ çekme oranına sahip kaplar için kalıp açısının sertlik dağılımı üzerindeki etkisi verilmiştir. Şekiller incelendiğinde yine kap tabanından kap ağzına doğru çıkıldıkça sertlik değerlerinin arttığı, en düşük sertlik dağılımının $\alpha=5^{\circ}$ lik kalıpta, en yüksek sertlik dağılımının ise $\alpha=15^{\circ}$ 'lik kalıpta elde edildiği görülmektedir. Sertliğin, kap ağzına doğru malzeme yığılmalarının deformasyon sertleşmelerini beraberinde getirmesinden dolayı arttığı, elde edilen kaplar ve sertlik ölçüm sonuçlarından kalıp açısının malzeme akışını kolaylaştırması neticesinde yığılmaların(aşırı deformasyonun) önlenmesi ve dolayısı ile de sertliğin azalmasına yol açtığı söylenebilir. 


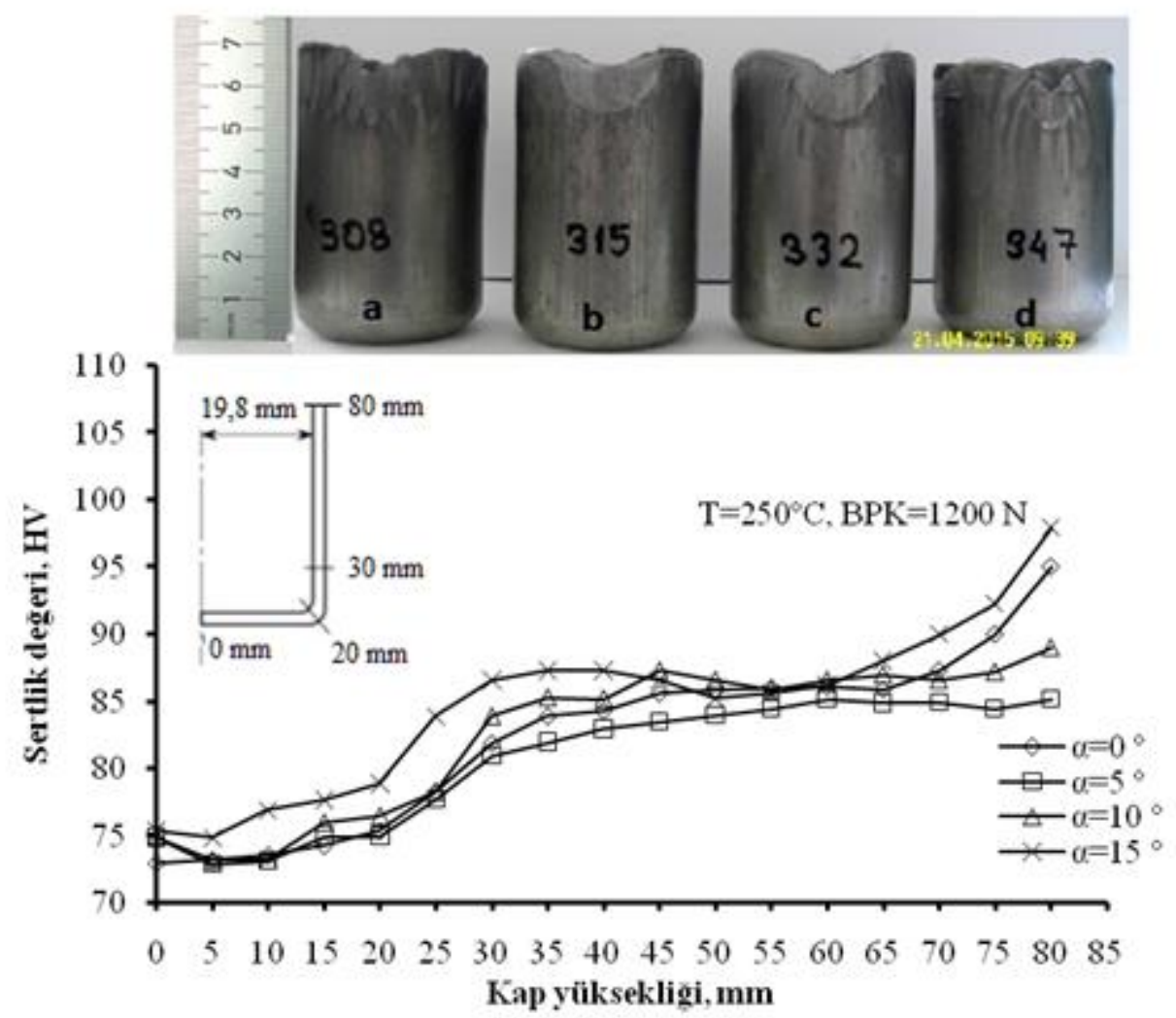

Şekil 8. 2,75 LÇO için kalıp açısının( $\alpha$ ) $250^{\circ} \mathrm{C}^{\prime}$ de sertlik dağılımı üzerindeki etkisi, a) $0^{\circ}$, b) $5^{\circ}$, c) $10^{\circ}$, d) $15^{\circ}$

Şekil 9'de sıcaklığın kabın alt ve üst bölgelerinden elde edilen bileziklerde oluşan açılma miktarına etkisi verilmiştir. Şekil incelendiğinde kabın radyüs bölgesinin hemen üzerinden(alt bilezik) alınan bilezikteki açılma miktarının kabın ağız kısmına yakın bölgeden(üst bilezik) alınan bilezikteki açılma miktarından daha fazla olduğu görülmektedir. Üst bilezikteki geri yaylanma miktarının düşük olmasının sebebi kap ağzındaki yığılma sonucu oluşan deformasyon sertleşmesinin geri yaylanmaya neden olan teğetsel gerilmeleri azaltmasıdır[7]. Yine sıcaklık göz önüne alındığında her iki bilezikte de sicaklık arttıkça geri yaylanma miktarının düştüğü görülmektedir. Özellikle sıcaklık $250^{\circ} \mathrm{C}$ 'ye çıktığında çok daha belirgin olmaktadır. Açılma miktarı, sıcaklığın sertlikle olan ilişkisini de ortaya koymaktadır. Sıcaklık arttıkça sertlik ve açılma miktarının düştüğü görülmektedir.

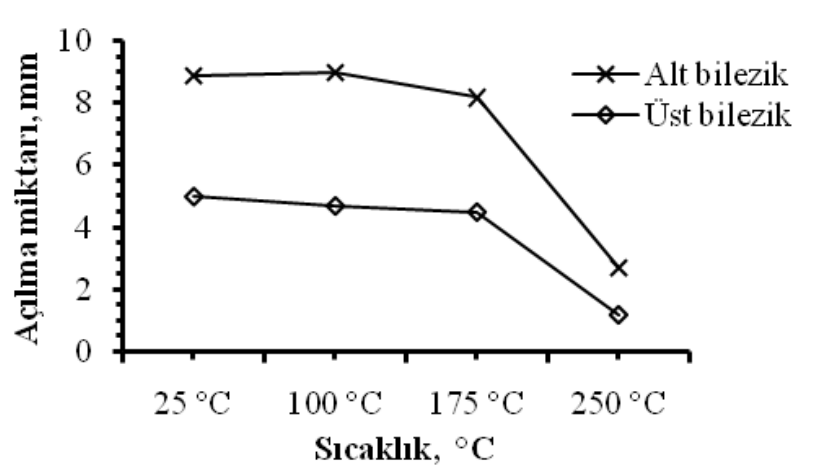

Şekil 9. Sıcaklığın bileziklerdeki acıkma miktarına etkisi

\section{DEĞRLENDİRME VE SONUÇ}

Bu çalışma, belirlenen sıcaklıklar, baskı plakası kuvvetleri ve kalıp yüzey açılarının elde edilen kapların sertliğine etkisinin belirlenmesi amacı ile yapılmıştır. Çalışma neticesinde çıkarılan genel sonuçlar aşağıda verilmiştir.

Üretilen kaplarda deformasyon sonucu oluşan sertlik kaplardaki geri yaylanma ve dolayısı ile de gerilmeler hakkında önemli bilgiler vermektedir[7]. Çalışmadan sıcaklık arttıkça sertliğin düştüğü, kalıp açısı arttıkça sertliğin $\alpha=10^{\circ}$ 'ye kadar düştüğü daha sonra yeniden arttığ 1 ve bu çalışma için seçilen baskı plakası kuvvetlerinin etkisinin çok az olduğu belirlenmiştir. Yine çalışmadan en düșük sertliğin kap tabanında en büyük sertliğin de en fazla deformasyona uğrayan kap ağzında olduğu görülmüştür. Ayrıca LÇO 2,14'de 2,75'e çıkarak \%28,5'luk bir artış olmasına rağmen sıcaklığında etkisi ile sertlik değerinde bir artış olmamıştır. Yapılan çalışma neticesinde sertliği etkileyen parametreler; sıcaklık, kalıp açısı ve baskı plakası kuvvet olarak sıralanabilir.

\section{KAYNAKLAR}

[1]. N. Şen and N. Kurgan, "Improving deep drawability of HC300LA sheet metal by warm forming" The International Journal of Advanced Manufacturing Technology, 2016, Volume 82, Issue 5-8, pp 985-995

[2]. O. Seçgin and V. Savaş, "An experimental investigation of forming load and side-wall thickness 
obtained by a new deep drawing die", Int J. Mater Form, 3:209-213, (2010)

[3]. C. Özek and E. Ünal, "The effect of die/blank holder angles on limit drawing ratio and wall thickness in deep drawing of square cups", Journal of the Faculty of Engineering and Architecture of Gazi University, Vol 27, No 3, 615-622, (2012).

[4]. D.L. Greene and J. DiCicco,"Engineering-economic analyses of automotive fuel economy potential in the United States". ORNL/TM-2000/26, Oak Ridge National Laboratory, Oak Ridge, TN, (2000).

[5]. M. Cotterell, J. Schambergerova, J. Ziegelheim and J. Janovecb, "Dependence of micro-hardness on deformation of deep-drawing sheet metal", Journal of Materials Processing Technology, Volume 124, Issue 3, 20 June 2002, Pages 293-296.

[6]. G. Kim and O. Kwon, Formation of abnormally coarse grain structure in cold rolled strip, in: Proceedings of the THERMEC'88 International Conference on Physical Metallurgy of Thermo-mechanical Processing of Steels and Other Metals, 1988, pp. 668-673.

[7]. C. Özek and V. Taşdemir, "Experimental investigation of the effects of blank holder force and die surface angle on the warm deep drawing of AA5754-O alloy", Journal of the Faculty of Engineering and Architecture of Gazi University 32:1 (2017) 193-201.

[8]. S. Tsuchida, K. Ito, H. Tanaka and N. Kanetake, "Strain and hardness distributions in the cup wall drawn with ironing of 3004-H19 aluminum alloy sheets", Journal of Japan Institute of Light Metals, Vol. 59, No. 1, 2009, pp. 24-29.

[9]. B. Lela, I. Duplančić and D. Bajić, "Parametric and non-parametric modelling of earing and hardness of deep drawn cups", Materials Science and Technology, 2009, Vol.25 No: 8.

[10]. W.C. Emmens "Hardening in Deep Drawing", IDDRG Working Group Meetings, June 8-9, 2000, Ann Arbor, MI, USA.

[11]. K. Farhoud, A.S. Khan and A. Pandey, "Negative to positive strain rate sensitivity in $5 \mathrm{xxx}$ series aluminum alloys:experiment and constitutive modelin", Int. J. Plast., 55 (0), 232-46, 2014.

[12]. C. Bernard, J. Coër, H. Laurent, P. Chauvelon and P.Y. Manach, "Relationship between local strain jump sand temperature bursts due to the Portevin-Le Chatelier effect in an Al-Mg alloy", Exp. Mech., 53 (6), 1025-32, 2013. 